\title{
FAKTOR YANG MEMPENGARUHI PELAKSANAAN P4K OLEH BIDAN DI DINAS KESEHATAN KABUPATEN KENDAL
}

\author{
Rifki trijayanti siwi \\ Email : siwirifki@gmail.com \\ Program Studi D III KebidananSTIKES Widya Husada Semarang \\ J1. Subali Raya No. 12 Krapyak Semarang \\ Telp/Fax (024)7612988
}

\begin{abstract}
ABSTRAK
Berdasarkan data terbaru, di akhir 2016 kematian Ibu di Kabupaten Kendal mencapai 19 kematian. Program P4K merupakan salah satu program promosi kesehatan yang dilaksanakan di Kabupaten Kendal yang bertujuan untuk menurunkan kematian ibu akibat komplikasi. Tujuan penelitian ini adalah mengetahui pelaksanaan P4K oleh bidan di Dinas Kesehatan Kabupaten Kendal. Jenis penelitian ini adalah penelitian kualitatif dengan menggunakan pendekatan fenomenologis. Teknik pengumpulan data dengan cara wawancara mendalam (depth interview) pada informan utama dan informan triangulasi. Jumlah informan utama 4 orang bidan desa dan informan triangulasi sebanyak 4 orang ibu hamil dan 2 orang bidan coordinator Dinas Kesehatan Kaupaten Kendal. Pengambilan informan menggunakan cara purposive sampling. Analisis data dilakukan sebelum dilapangan, saat di lapangan menggunakan cara data collections, data reduction, data display dan concluions, setelah selesai di lapangan. Hasil penelitian menunjukkan bahwa pelaksanaan Program P4K oleh bidan belum optimal, pengetahuan bidang tentang P4K sudah baik. Ada ibu hamil yang tidak tahu tentang P4K dan stiker P4K.. Komunikasi antara bidan, kader, dan pihak-pihak yang terkait di lapangan terutama dalam pelaksanaan program P4K sudah berjalan dengan baik. Bidan sudah memiliki kompetensi dalam hal pendidikan dan pengetahuan. kader masih ada yang memiliki kompetensi yang kurang.
\end{abstract}

Kata Kunci : Bidan Desa, Bidan Koordinator, Ibu Hamil, P4K

\section{Pendahuluan}

Angka Kematian Ibu (AKI) merupakan salah satu indikator untuk melihat derajat kesehatan perempuan. Setiap tahun, di seluruh dunia, diperkirakan terjadi 358.000 kematian ibu dan sekitar 99\% kematian tersebut terjadi di negara berkembang yang miskin dan sekitar 67\% merupakan sumbangan sebelas negara temasuk Indonesia. ${ }^{1}$

Perhatian khusus harus diberikan terhadap peningkatan kesehatan ibu termasuk bayi baru lahirnya adalah dengan melaksanakan berbagai upaya percepatan penurunan Angka Kematian Ibu (AKI). Salah satu upaya terobosan untuk percepatan penurunan AKI adalah Program Perencanaan Persalinan dan Pencegahan Komplikasi (P4K) dengan Stiker. Kegiatan P4K dengan Stiker juga merupakan salah satu instrument yang efektif dalam mencapai sasaran MDGs terutama dalam hal penurunan AKI, yang telah terintegrasi sebagai satu kegiatan dari Desa Siaga. ${ }^{5}$ Pada awalnya Kemenkes mencanangkan Program Perencanaan Persalinan dan Pencegahan
Komplikasi (P4K) pada tahun 2007, yang ditindaklanjuti dengan surat edaran Menteri Kesehatan Nomor 295 Tahun 2008 tentang percepatan pelaksanaan Program Perencanaan Persalinan dan Pencegahan Komplikasi (P4K) dengan program pemasangan stiker dan surat edaran Menteri Dalam Negeri Nomor 441.7/1935. SJ tahun 2008 tentang Percepatan Pelaksanaan Program Perencanaan Persalinan dan Pencegahan Komplikasi (P4K) dengan stiker. ${ }^{3}$ Program Perencanaan Persalinan dan Pencegahan Komplikasi (P4K) yang dicanangkan pemerintah bertujuan memantau kehamilan menuju persalinan yang aman dan selamat pada tingkat pelayanan dasar dengan sasarannya adalah seluruh ibu hamil. Indikator P4K adalah dengan pemasangan stiker $\mathrm{P} 4 \mathrm{~K}$ yang mencantumkan penolong persalinan, tempat persalinan, pendamping persalinan, transportasi, dan calon donor darah. Output dari program ini adalah : 1) semua ibu hamil terdata dan rumah tertempel stiker, 2) pelayanan ANC sesuai standar, 3) pelayanan persalinan sesuai standar, 4)pelayanan 
nifas sesuai standar, 5) ibu dan keluarga punya rencana persalinan termasuk $\mathrm{KB}$, 6) keluarga menyiapkan biaya persalinan, 7) terlibat masyarakat seperti forum peduli KIA/pokja posyandu, 8) pelayanan konstrasepsi, dan 9) kerjasama antara bidan, tenaga puskesmas pembantu, forum peduli KIA, dukun bayi dan pendamping persalinan. $^{3}$

Kab. Kendal adalah salah satu kabupaten yang sangat dekat dengan Kota Semarang sebagai Ibu Kota Jawa Tengah, dimana pelayanan kesehatan sudah cukup baik, namun masih berkontribusi banyak pada angka kematian ibu dan anak di Jawa tengah. Pada tahun 2012, Angka Kematian Ibu (AKI) adalah 131,88/100.000 Kelahiran Hidup, angka tersebut hanya menurun sedikit pada tahun berikutnya, pada tahun 2013 Angka kematian ibu tercatat 128,78/100.000 Kelahiran Hidup, tahun 2014 tercatat 119,97/100.000 KH, dan tahun 2015 sebesar 148,81/100.000 Kelahiran Hidup (Dinkes Kab. Kendal, 2015). Berdasarkan data terbaru, di akhir 2016 kematian Ibu di Kabupaten Kendal mencapai 122,48/100.000 Kelahiran Hidup. ${ }^{4,5}$

Program P4K merupakan salah satu program promosi kesehatan yang dilaksanakan di Kab. Kendal. Namun berdasarkan laporan USAID mengenai program $\mathrm{P} 4 \mathrm{~K}$ terdapat beberapa hal yang berpotensi menghambat pencapaian tujuan $\mathrm{P} 4 \mathrm{~K}$ dan penurunan AKI, seperti Lemahnya Perencanaan dan penganggaran $\mathrm{BOK}$ untuk menguatkan program $\mathrm{P} 4 \mathrm{~K}$ sehingga kegiatan implementasi dan monitoring masih belum menyentuh aspek-aspek mendukung P4K. Kurangnya pemahaman ibu hamil atau masyarakat tentang kehamilan dan pencegahan komplikasi. ${ }^{6}$ Bidan sangat sedikit memberikan waktu untuk peningkatan informasi (temu wicara) termasuk informasi yang berkaitan dengan risiko dan komplikasi, dan ASI. Banyak ibu hamil memeriksa kehamilannya tanpa didampingi oleh suami sehingga bidan dan tenaga kesehatan lainnya mengalami kesulitan dalam menyampaikan informasi-informasi penting kepada pengambil keputusan dalam keluarga. Keterlibatan masyarakat melalui forum atau kelompok lain belum dikelola dengan baik oleh puskesmas. ${ }^{7}$

Keberhasilan pelaksanaan kebijakan program $\mathrm{P} 4 \mathrm{~K}$ dipengaruhi oleh banyak faktor. Struktur dalam pelayanan yang tidak kondusif terhadap pelaksanaan kebijakan menyebabkan ketidakefektifan dan menghambat jalannya pelaksanaan kebijakan. Sumberdaya juga merupakan hal penting dalam pelaksanaan program $\mathrm{P} 4 \mathrm{~K}$ yaitu Bidan itu sendiri dan Puskesmas sebagai tempat pemberi pelayanan. Dengan demikian apabila pelaksana memiliki sikap positif dan dukungan terhadap pelaksanaan program $\mathrm{P} 4 \mathrm{~K}$ tidak menutup kemungkinan program $\mathrm{P} 4 \mathrm{~K}$ tersebut berjalan sesuai dengan rencana awal.

Peneliti menggunakan informan bidan desa dalam penelitian ini karena bidan yang bersentuhan langsung dengan masyarakat terutama dengan ibu hamil dan kader di lapangan. Program P4K dan pelayanan ibu hamil merupakan tugas pokok dan funsi bidan yang harus dilaksanakan di lapangan. Sebagaimana yang disampaikan oleh Menteri Kesehatan Republik Indonesia bahwa semua pelaksana program dilapangan baik di Puskesmas maupun Bidan di Desa agar melaksanakan P4K dengan Stiker ini secara berkesinambungan. Lebih jauh Menteri Kesehatan menyatakan bahwa Bidan di Desa agar aktif memfasilitasi pemerdayaan semua pemangku kepentingan yang terdiri dari ibu hamil, suami, keluarga, dan masyarakat dengan mengajak mereka untuk mendata, mencatat, dan memantau intensif setiap ibu hamil melalui penempelan stiker di setiap rumah ibu hamil dan memastikan diberkannya pelayanan kesehatan sesuai standar sehingga ibu melahirkan dan bayi yang dilahirkan aman dan selamat 2 


\section{Metode Penelitian}

Penelitian ini merupakan penelitian deskriptif observasional, menggunakan metode kualitatif dan pendekatan fenomenologis yang bertujuan untuk mendapatkan pemahaman secara mendalam dan gambaran penafsiran dari sudut pandang Bidan Desa di dalam pelaksanaan $\mathrm{P} 4 \mathrm{~K}{ }^{8}$

\section{Hasil Dan Pembahasan}

\section{Pengetahuan bidan tentang P4K dengan stiker}

Peneliti melakukan eksplorasi tentang pengetahuan bidan pada program P4K di Kabupaten Kendal dengan 5 fokus pertanyaan mengenai pengetahuan bidan tentang program $\mathrm{P} 4 \mathrm{~K}$ yaitu pengertian $\mathrm{P} 4 \mathrm{~K}$, tujuan $\mathrm{P} 4 \mathrm{~K}$, manfaat $\mathrm{P} 4 \mathrm{~K}$ dengan stiker pada ibu hamil, komponen atau informasi yang terdapat pada stiker P4K.

Berdasarkan hasil wawancara terhadap informan atau sumber data utama mengenai pengetahuan bidan tentang P4K. peneliti memperoleh variasi jawaban diantara masing-masing informan atau sumber data.

Mengenai pengertian tentang $\mathrm{P} 4 \mathrm{~K}$ Dari 4 orang bidan selaku informan atau sumber data ada 1 orang informan yang menyebutkan secara lengkap mengenai pengertian $\mathrm{P} 4 \mathrm{~K}$. sementara ada 3 informan atau sumber data lainnya menyebutkan secara kurang lengkap. Namun inti jawaban dari informan atau sumber data menurut peneliti sudah benar. Selanjutnya peneliti mencoba untuk mengeksplorasi kembali kepada bidan selaku informan atau sumber data mengenai tujuan program P4K. Ratarata informan atau sumber data sudah mengetahui tentang tujuan program P4K. Ketika peneliti menanyakan mengenai manfaat $\mathrm{P} 4 \mathrm{~K}$ dengan stiker pada ibu hamil. Keempat informan atau sumber data menjawab hampir sama yaitu mencegah terjadinya komplikasi atau kematian ibu dan bayi. Selanjutnya peneliti mencoba mengeksplorasi lebih dalam pengetahuan informan atau sumber data mengenai informasiinformasi apa sajakah yang tertera dalam stiker P4K. hasil jawaban responden bervariasi. Ada satu orang informam yang berhasil menjawab lengkap dan urut sesuai dengan informasi yang ada dalam stiker. Ada satu orang informan yang menjawab lengkap namun tidak urut. Sementara 2 informan menjawab kurang lengkap.

Berdasarkan hasil wawancara kepada informan atau sumber data utama mengenai pengetahuan informan atau sumber data utama mengenai pengetahuan tentang $\mathrm{P} 4 \mathrm{~K}$ yang meliputi : pengertian $\mathrm{P} 4 \mathrm{~K}$, tujuan $\mathrm{P} 4 \mathrm{~K}$, manfaat P4K dengan stiker pada ibu hamil, komponen atau informasi yang tersedia pada P4K. sebagian besar informan atau sumber data sudah mengetahui. Dengan adanya pengetahuan tersebut diharapkan dapat diaplikasikan di lapangan khususnya kepada ibu hamil untuk mencegah terjadinya komplikasi pada ibu hamil.

Karakteristik personal yang mencakup : dorongan, sifat / watak, citra diri, pengetahuan akan menentukan bagaimana perilaku orang dalam bekerja. Semakin terampil seseorang/semakin ahli orang dalam pekerjaan tersebut, maka akan semakin mendorong penampilan kerja yang baik/unggul ${ }^{5,10}$

Dengan demikian pengetahuan bidan desa tentang program P4K dengan stiker menjadi penting dan bermanfaat untuk pelaksanaan program P4K. Dengan pengetahuan yang kurang akan memungkinkan bidan desa kurang dapat memahami fenomena dan memecahkan suatu masalah dalam pelaksanaan program $\mathrm{P} 4 \mathrm{~K}$ dengan stiker didesanya.

Namun pengetahuan bidan desa tentang program $\mathrm{P} 4 \mathrm{~K}$ dengan stiker belum tentu akan berbanding lurus dengan kinerja bidan desa dalam pelaksanaan program $\mathrm{P} 4 \mathrm{~K}$ dengan stiker. Hal ini sesuai dengan teori yang menyatakan bahwa kedalaman dan keluasan pengetahuan belum tentu berbanding lurus dengan sikap dan perilaku yang unggul. kinerja aktual seseorang ditentukan oleh kompentensi sikap dan perilaku. 
Peningkatan pengetahuan tidak selalu menyebabkan perubahan perilaku. Pengetahuan merupakan faktor penting tidaknya dalam perubahan perilaku. Perilaku dan tindakan dapat dipengaruhi oleh beberapa faktor, salah satunya adalah pengetahuan. Pengetahuan merupakan domain yang sangat penting dalam membentuk perilaku seseorang. Pengetahuan diperlukan sebagai dorongan berfikir dalam menumbuhkan kepercayaan diri maupun dorongan sikap dan perilaku, sehingga dapat dikatakan bahwa pengetahuan merupakan stimuli terhadap tindakan seseorang. Disamping itu, perilaku yang dalam pembentukannya didasari oleh pengetahuan akan bersifat lebih langgeng. ${ }^{8,10}$

Pihak yang terkait dalam pelaksanaan Program Perencanaan Persalinan dan Pencegahan Komplikasi (P4K).

Peneliti mencoba menggali secara mendalam kepada informan atau sumber data utama yaitu bidan melalui wawancara mendalam (depth interview) mengenai pihak-pihak yang terlibat dalam pelaksanaan Program Perencanaan Persalinan dan Pencegahan Komplikasi (P4K) di Kabupaten Kendal khususnya di dua Wilayah Puskesmas yaitu Wilayah Puskesmas Kaliwungu dan Wilayah Puskesmas Cepiring sebagai lokasi penelitian. Dalam menggali phak-pihak yang terkait dalam Pelaksanaan Program Perencanaan Persalinan dan Pencegah Komplikasi di Kabupaten Kendal, peneliti 2 fokus utama yaitu 1) pihak yang terkait dalam pemasangan stiker $\mathrm{P} 4 \mathrm{~K}, 2$ ) pihak yang terkait dalam pertemuan atau pengawasan pelaksanaan program $\mathrm{P} 4 \mathrm{~K} .{ }^{2}$

Bekaitan dengan pertanyaan mengenai pihak yang terlibat dalam pemasangan stiker keempat informan mempunyai jawaban yang hampir sama dan sudah bisa dianggap benar. Ketika informan atau sumber data ditanya mengenai pihak yang terlibat dalam pertemuan atau pengawasan pelaksanaan program $\mathrm{P} 4 \mathrm{~K}$. Informan atau sumber data mempunyai kemiripan jawaban yaitu rata-rata menjawab bidan desa, PKK, tokoh agama, tokoh masyarakat, dan lain-lain. Sebagai pemberi materi dalam pertemuan adalah bidan desa. Keterlbatan bebagai pihak dalam program Perencanaan Persalinan dan Pencegahan Komplikasi (P4K) di lapangan suda sesuai dengan teori tentang P4K di bawah ini. ${ }^{2}$

Ketika informan atau sumber data ditanya mengenai pihak yang terlibat dalam pertemuan atau pengawasan pelaksanaan program P4K. Informan atau sumber data mempunyai kemiripan jawaban. Rata-rata informan atau sumber data menjawab bahwa pihak yang terkait dalam pertemuan atau pengawasan pelaksanaan program $\mathrm{P} 4 \mathrm{~K}$ adalah bidan wilayah, ibu PKK, forum KIA, Desa Siaga, Tokoh Agama, Tokoh Masyarakat. $^{2,4}$

Setelah dilakukan wawancara mendalam (depth interview) dengan informan triangulasi untuk pengecekan keabsahan ata yang disampaikan oleh informan atau sumber data utama. Ada kesesuaian jawaban informan triangulasi (ibu hamil) dengan inorman atau sumbe data utama. Informan atau sumber data utama mengaakan bahwa bidan ikut dalam pertemuan atau pengawasan pelaksanaan Program P4K di lapangan. Selanjutnya Peneliti menanyakan lebih lanjut apakah ada orang lain yang ikut dalam pertemuan tersebut. Dari 4 orang informan triangulasi 1 orang yang menjawab tidak tahu. Kaena hanya satu orang yang tidak tahu smentara 3 orang informan triangulasi (ibu hamil) tahu dan jawaban antara informan triangulasi (ibu hamil) dengan informan atau sumber data utama ada kesesuaian jawaban. Dimana menurut informan triangulasi (ibu hamil) menyatakan bahwa perangkat dea, kader, ibu PKK, kepala desa, forum KIA, desa siaga juga ikut dalam pelaksanaan kegiatan program $\mathrm{P} 4 \mathrm{~K} .{ }^{5}$

Berkaitan dengan pelaksanaan pemasangan stiker. Ada kesesuaian jawaban antara informan triangulasi (ibu hamil) dengan informan atau sumber 
data utama. Menurut informan triangulasi (ibu hamil) yang ikut erlibat dalam pemasangan stiker di rumah ibu hamil adalah bia, kader, kepala dusun.

Pengecekan kredibiitas data yang disampaikan oleh informan atau smber data utama dilakukan melalui wawancara mendalam dengan informan riangulasi (bidan koordinator) sebanyak 2 orang. Bekaitan dengan pertanyaan mengenai pihak yang terlibat dalam pemasangan stiker kedua informan triangulasi (bidan koordinator) mempunyai jawaban yang hampir samadan ada kesesuaian dengan informan atau sumber data utama. Menurut informan triangulasi (bidan koordinator) yang terlibat dalam peaksanaan pemasangan stiker yaitu bidan desa, kader, ibu PKK, forum KIA, desa siaga, dan lain-lain. Sdangkan pihak yang terlibat dalam pertemuan dan pengawasan pelaksanaan program P4K menurut informan triangulasi (bidan koordinator) adalah ibu PKK, forum KIA, kader, tokoh agama, tokoh masyarakat. Jawaban dari informan triangulasi (bidan koordinator) ada kesesuaian dengan jawaban dari infrman atau sumber data utama.

Meningkatkan keterlibatan tokoh masyarakat baik formal maupun non formal, dukun / pendamping persalinan dalam kelompok masyarakat dalam perencanaan persalinan dan pencegahan komplikasi dengan stiker, dan KB pasca persalinan sesuai dengan perannya masing-masing ${ }^{1}$

faktor yang menentukan terjadinya perubahan perilaku adalah faktor reinforsing atau faktor penguat. Dimana yang termasuk dalam faktor tersebut salah satunya adalah dukungan tenaga kesehatan. Dukungan tenaga kesehatan dalam melakukan suatu tindakan akan memperkuat terjadinya seseorang untuk melakukan sebagaimana yang diinginkan oleh petugas kesehatan. Terjadinya perubahan perilaku tersebut juga bisa terjadi karena adanya dukungan masyarakat, dukungan praktisi promosi kesehatan dan pendidik kesehatan. ${ }^{8}$
Dalam kehamilan bentuk peran atau dukungan kader dan petugas kesehatan dapat berupa memberikan komunikasi, informasi, edukasi / KIE agar memeriksakan kehami, lan secara teratur,pengenalan dini adanya tanda perdarahan sebelum bayilahir, merujuk segera ke bidan/ puskesmas bila ada perdarahan,membuat perencanaan persalinan bersama suami dan keluarga beserta tenaga kesehatan. ${ }^{8}$

\section{Kesimpulan}

Pelaksanaan program P4K dengan stiker di Dinas Kesehatan Kabupaten Kendal sudah berjalan namun masih belum optimal karena ada responden yang masih belum paham tentang stiker P4K.Semua informan atau sumber data utama telah mengetahui tentang pengertian $\mathrm{P} 4 \mathrm{~K}$, manfaat $\mathrm{P} 4 \mathrm{~K}$, model $\mathrm{P} 4 \mathrm{~K}$ pada ibu hamil, dan informasiinformasi yang tersedia di stiker $\mathrm{P} 4 \mathrm{~K}$. Berdasarkan hasil wawancara mendalam (depth interview) tentang pihak yang terkait dalam pelaksanaan program perencanaan persalinan dan pencegahan komplikasi. Terdapat kesesuaian jawaban antara informan atau sumber data utama dengan informan triangulasi (bidan koordinator) maupun dengan informan triangulasi (Ibu hamil). Adapun jawabannya bahwa pihak yang terkait adalah bidan desa, kader, ibu PKK, forum KIA, tokoh agama dan tokoh masyarakat. Komunikasi antara bidan dengan kader, PKK, Forum KIA, Masyarakat, Tokoh Agama dan Tokoh Masyarakat sudah berjalan dengan baik. Hal ini bisa dilihat dari hasil wawancara dengan ibu hamil.

\section{Daftar Pustaka}

[1] World Health Organization. Trends in maternal mortality: 1999 to 2008. Geneva: World Health Organization press; 2010.

[2] Depkes RI. Pedoman Program Perencanaan Persalinan dan Pencegahan Komplikasi dengan Stiker. USAID. 2015. 
[3] Depkes RI. Pedoman Program Perencanaan Persalinan dan Pencegahan Komplikasi (P4K) dengan Stiker dalam rangka mempercepat penurunan AKI. Jakarta: Depkes RI; 2009.

[4] Dinkes Kab. Kendal. Laporan tahunan pelaksanaan P4K Kab. Kendal tahun 2016; Dinkes Kab. Kendal; 2017

[5] Dinkes Kab. Kendal. Laporan Angka Kematian Ibu Kab. Kendal tahun 2016. Kendal : Dinkes Kab. Kendal; 2017

[6] WHO, Maternal Mortality in 2005: Estimates Developed by WHO, UNICEF, UNDFPA and the World Bank:WHO; 2007
[7] Dinkes Kab. Kendal. Profil Kesehatan Kabupaten Kendal tahun 2014. Kendal : Dinkes Kab. Kendal;2015

[8] Notoatmodjo, S. Promosi Kesehatan Teori dan Aplikasi. Jakarta: PT Rineka Cipta, 2005

[9] Sunyoto. D. Teori, Kuesioner, dan Proses Analisis Data Perilaku Organisasional. Jogjakarta. Center for Academic Publishing Service. 2013.

[10] Green, Lawrence W; Health Promotion Planning: An Educational and Environmental Approach. Second Edition. Mayfield Publishing Company. Mountain View-Toronto-London. 2000. 